\title{
Metodologias ativas Que empregam Tecnologias Digitais de INFORMAÇÃO E COMUNICAÇÃO (TDIC) NO ENSINO MÉDIO INTEGRADO
}

\author{
ACTIVE METHODOLOGIES USING INFORMATION AND COMMUNICATION TECHNOLOGY \\ (ICT) APPLIED INTO HIGH SCHOOL
}

METODOLOGÍAS ACTIVAS QUE USAN TECNOLOGÍAS DE INFORMACIÓN Y COMUNICACIÓN DIGITAL (TDIC) EN LA ESCUELA SECUNDARIA INTEGRADA

\author{
Simone Rodrigues de \\ Magalhães \\ (iD) 9 \\ Doutora em Ciências no programa \\ Recursos Florestais (USP) \\ Professora Substituta do IFNMG \\ Campus Arinos \\ simagalhaes@gmail.com
}

\section{Laerte Mateus Rodrigues (iD) 9}

Doutor em Bioinformática Professor EBTT lotado no IFMG

Campus Ribeirão das Neves

laerte.rodrigues@ifmg.edu.br

\section{Cláudio Alves Pereira iD 9}

Doutorando no Programa de PósGraduação em Educação da Universidade Federal do Espírito Santo (UFES)

Mestre em Educação (UFLA)

claudioapessoal@gmail.com

\begin{abstract}
Resumo
O objetivo deste trabalho é apresentar um mapeamento sistemático de literatura do uso de metodologias ativas que empregam tecnologias digitais de informação e comunicação (TDIC) no processo de ensino-aprendizagem, no Ensino Médio Integrado dos Institutos Federais. A busca dos trabalhos foi feita no site Google Acadêmico e a escolha dos trabalhos foi feita por meio de votação dos autores de forma que somente os trabalhos com dois votos ou mais seriam analisados, o corpus analisado foram cinco artigos e uma tese que usaram TDIC aliadas a quatro metodologias ativas em disciplinas do Ensino Médio e Ensino Técnico no ambiente dos Institutos Federais. Os resultados apontam que o planejamento de práticas pedagógicas, que aliem metodologias ativas e tecnologia, potencializam o processo de ensino-aprendizagem de estudantes em diferentes disciplinas com diferentes meios de aprendizagem, seja por gamificação, peer instruction, aprendizagem baseada em projetos ou produção autoral por meio de dispositivos computacionais.
\end{abstract}

Palavras-chave: Métodos Ativos. Educação Profissional Integrada. Mapeamento Sistemático.

Recebido em: 7 de julho de 2021.

Aprovado em: 9 de outubro de 2021.

Como citar esse artigo (ABNT):

MAGALHÃES, Simone Rodrigues de; RODRIGUES, Laerte Mateus; PEREIRA, Cláudio Alves. Metodologias ativas que empregam Tecnologias Digitais de Informação e Comunicação (TDIC) no ensino médio integrado. Revista Prática Docente, v. 6, n. 3, e083, 2021.

http://doi.org/10.23926/RPD.2021.v6.n3.e083.id1257 


\section{Abstract}

The objective of this work is to present a systematic literature mapping of the use of active methodologies applied with digital information and communication technologies (TDIC) in the teaching-learning process in Integrated High School at Federal Institutes. The search for the works was made on the Google Academic site and the choice of works was made by voting the authors so that only works with two votes or more would be analyzed. The analyzed corpus consisted of five articles and a thesis that used TDIC allies to four active methodologies in subjects of High School and Technical Education in the environment of Federal Institutes. The results show that the planning of pedagogical practices, which combine active methodologies and technology, enhance the teaching-learning process of students in different disciplines with different means of learning, whether by gamification, peer instruction, projectbased learning or authorial production by through computational devices.

Keywords: Active Methodolgy. Professional Education for High School Students. Systematic Mapping.

\section{Resumen}

El objetivo de este trabajo es presentar un mapeo sistemático de la literatura sobre el uso de metodologías activas que emplean tecnologías de la información y la comunicación digitales (TDIC) en el proceso de enseñanza-aprendizaje en Bachillerato Integrado de Institutos Federales. La búsqueda de los trabajos se realizó en el sitio Google Academic y la elección de los trabajos se realizó mediante votación de los autores para que solo se analizaran los trabajos con dos votos o más. El corpus analizado estuvo conformado por cinco artículos y una tesis que utilizó aliados del TDIC a cuatro metodologías activas en asignaturas de Bachillerato y Educación Técnica en el ámbito de los Institutos Federales. Los resultados muestran que la planificación de prácticas pedagógicas, que combinan metodologías activas y tecnología, potencian el proceso de enseñanza-aprendizaje de los estudiantes en diferentes disciplinas con diferentes formas de aprendizaje, ya sea por gamificación, instrucción entre pares, aprendizaje basado en proyectos o producción autoral por medio de dispositivos computacionales.

Palabras clave: Métodos Activos. Educación Profesional Integrada. Mapeo Sistemático. 


\section{INTRODUÇÃo}

Ao longo da história, diferentes métodos de ensino-aprendizagem têm sido desenvolvidos, sempre com foco na busca pela melhoria na aprendizagem (NUNES, 2019). Recentemente, diferentes estratégias centradas no aluno têm sido pesquisadas e desenvolvidas, sendo comumente denominadas Metodologias Ativas (MA). Nas MA, os alunos observam e refletem sobre a realização da tarefa, sendo estimulados a encontrar diferentes estratégias para explicar um fenômeno. Nesse processo, o professor atua como mediador ou orientador, ou seja, ele guia os alunos por meio de reflexões e questionamentos necessários para executar a atividade e promover o conhecimento (SANTOS; RIBEIRO, 2018; OECHSLER; MANERICH; SILVA, 2019).

Diferentes benefícios das MA em relação aos "métodos tradicionais de ensino" têm sido descritos na literatura, sendo tais métodos tradicionais aqueles em que os alunos são elementos passivos e o conhecimento é transmitido pelo professor (OLIVEIRA, 2019). De forma geral, as pesquisas relatam maior motivação dos estudantes (ESTEVES; ARAÚJO, 2020), aulas mais dinâmicas e com maior participação e interação entre os alunos (OLIVEIRA; LIMA, 2018; SILVA et al., 2018, PANTOJA; VIEIRA; HANAN, 2019). Em termos de aprendizagem, dentre as possíveis contribuições das MA, estão: facilitar a aprendizagem (PANTOJA; VIEIRA; HANAN, 2019), contribuir com a aprendizagem colaborativa (SILVA, 2018) e/ou com a produção do conhecimento (OECHSLER; MANERICH; SILVA, 2019). Contudo tais resultados têm sido apontados em termos descritivos, com base na percepção do professor ou opinião dos estudantes, quase sempre obtidos por meio de questionários. Segundo Nunes (2019), a literatura científica apresenta poucos estudos comparativos sobre a eficiência dos métodos de ensino-aprendizagem.

O êxito das metodologias de ensino-aprendizagem, independente de qual se escolha, perpassa o tema da contextualização. A aprendizagem contextualizada tem amplo suporte pedagógico e psicológico, ocupando uma posição relevante no atual panorama educativo (FESTAS, 2015). Em termos das MA, onde o aluno é imprescindível para a realização da estratégia, a contextualização é indispensável (NUNES, 2019), visto a grande influência do conhecimento prévio e das observações dos estudantes durante o processo.

$\mathrm{Na}$ geração atual, a contextualização do aprendizado também implica em integrar os recursos das tecnologias digitais de informação e comunicação (TDIC) ao processo educativo. Segundo Santos e Ribeiro (2018), a geração atual nasceu cercada por tecnologia e, desde muito 
cedo, aprendeu a manipular jogos eletrônicos, redes sociais e internet. Estes jovens, que já nasceram em um mundo imerso nas TDIC, não devem mais permanecer em uma sala de aula onde o professor faz uso exclusivo do "pincel e quadro branco" (SALES et al., 2017). Santos e Ribeiro (2018) apontam para a urgência de lançar mão de estratégias que possibilitem o protagonismo do aluno e a integração das TDIC no processo de ensino-aprendizagem.

As TDIC podem ser abordadas como uma evolução das Tecnologias de Informação e Comunicação (TIC) para a era digital (SILVA, 2020). Ainda segundo o autor, as TDIC são "todas as ferramentas tecnológicas digitais que utilizamos para fins de criação, publicação e consumo de informação, além dos diversos componentes físicos e suas soluções que utilizamos para nos comunicar" (p. 147), podendo a comunicação ser feita por meio de dispositivos computacionais (como computadores, celulares, tablets etc.) e pelo uso de diferentes tipos de softwares de comunicação.

Sendo assim, o objetivo deste trabalho é apresentar um mapeamento sistemático da literatura da aplicação de MA, apoiadas por ferramentas de TDIC, aplicadas no ensino médio, mais especificamente em Institutos Federais. Por meio desta, visou-se detalhar os princípios básicos destas MA, de modo a enfatizar a importância das TDIC para suas aplicações, bem como detalhar os resultados obtidos pelos diferentes estudos que compuseram o corpus de análise. Por fim, este estudo buscou identificar uma tendência metodológica que se mostrasse própria ao EMI, em termos das MA.

\section{MAPEAMENTO SISTEMÁTICO DA LITERATURA}

O objetivo deste tipo de levantamento de dados é construir uma metassíntese sobre uma determinada área do conhecimento, a fim de apresentar os principais resultados e perspectivas do campo de pesquisa em questão. A natureza desse tipo de pesquisa é quantitativa e o seu resultado é construído a partir de uma busca em uma base bibliográfica (ou de várias bases), nas quais são escolhidos somente estudos que se mostram relevantes ao objeto de estudo, no qual serão discutidos os seus resultados (MUNN et al., 2018).

A primeira etapa deste processo buscou selecionar as bases bibliográficas a serem consultadas. A principal forma de busca nessas bases é por meio de palavras-chave; os estudos que possuírem o termo de busca, ou o conjunto desses, serão dados no resultado da pesquisa.

A priori, tais buscas tendem a ser genéricas e os resultados são imprecisos, pois a busca, por meio textual e por essas máquinas de busca, é feita na estrutura sintática e não semântica (ÁVILA; SOARES, 2012). Em função desse processo de aproximação do elemento desejado, 
a busca tende a retornar documentos que não fazem parte do contexto da pesquisa, sendo esses removidos de forma manual.

\subsection{Procedimento Metodológico}

Neste trabalho, a busca dos trabalhos foi realizada diretamente no sítio Google Scholar ou Google Acadêmico, uma base de dados científicos gratuita que, presumivelmente, lista todas as publicações da busca eletrônica (FALAGAS et al., 2008). As palavras-chave da pesquisa foram: "metodologia ativa", "técnico integrado" ou com a combinação "metodologia ativa" e "informática", tidas pelos pesquisadores como termos correlatos às TDIC (ABDULLAYEV, 2020; BASÍLIO et al., 2020). Foram aceitos somente trabalhos publicados no idioma português e publicados no período de janeiro de 2018 a 22 de abril de 2020 (data da coleta).

A etapa de filtragem dos estudos deu-se por avaliação dos três pesquisadores envolvidos neste estudo, em níveis distintos. Em cada uma das etapas, os trabalhos levantados pelo Google Scholar que obtiveram dois votos (dos três possíveis) continuou para a etapa seguinte. A primeira etapa consistiu na análise do título, a segunda etapa se deteve na análise do resumo, enquanto a última etapa focou na análise do objetivo, da metodologia e conclusões do estudo. Nessa terceira etapa, além de trabalhos não condizentes com o objeto deste estudo, também foram excluídos os trabalhos com metodologias incompletas e que não possibilitaram a compreensão da pesquisa, além daqueles em fase de proposta.

Ao final, os trabalhos que persistiram por estas três etapas fizeram parte da análise sistemática e compuseram o corpus do estudo. Dos 63 estudos levantados na base de dados do Google Scholar, apenas seis trabalhos se mostraram elegíveis para esta pesquisa. A Figura 1 apresenta a relação da quantidade de artigos selecionados em cada uma das etapas de filtragem dos artigos.

Figura 1 - Relação de trabalhos extraídos em cada uma das etapas de análise dos trabalhos extraídos do Google Scholar.

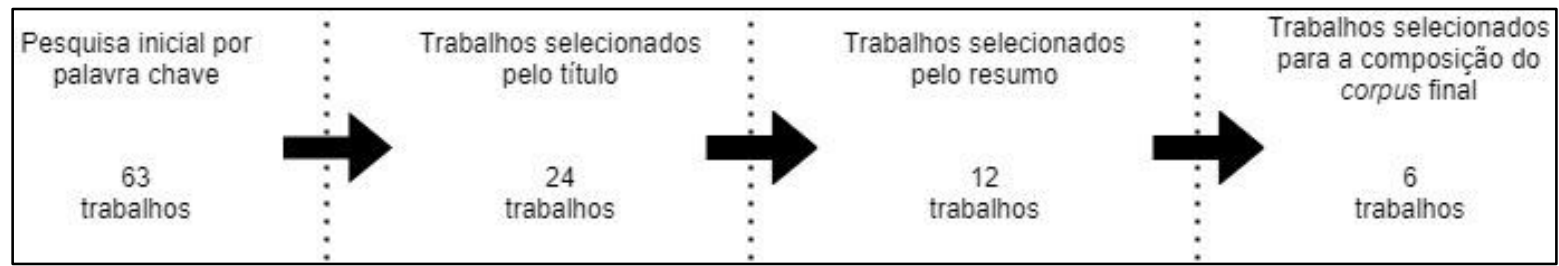

Fonte: Da pesquisa realizada. 


\section{RESUlTADOS E DISCUSSÃO}

Nesta seção, serão descritos a importância das TDIC para as MA, bem como os princípios básicos destas MA que atualmente têm sido aplicadas no EMI, ou seja, aquelas presentes nos seis estudos obtidos pelo processo metodológico descrito anteriormente, sendo cinco artigos e uma tese de Oliveira (2019).

Além da descrição das MA, esses estudos foram detalhados a fim de se investigar a tendência de uso das MA no EMI, suas possibilidades de ganhos no processo de ensinoaprendizagem e possíveis dificuldades de utilização.

\subsection{Metodologias ativas E AS TDIC}

O corpus desta pesquisa apontou a utilização de quatro MA aplicadas com auxílio das TDIC no EMI, a saber: (i) aprendizagem baseada em projetos (ABPj); (ii) gamificação; (iii) produção autoral; e (iv) sala de aula invertida. Quanto às TDIC, os hardwares mais utilizados foram o celular e o computador, enquanto o Kahoot destacou-se como o software preferido. Ressalta-se que alguns trabalhos não descreveram todas as TIDC empregadas para a aplicação da MA, sendo possível, pela leitura em profundidade, deduzir o uso do computador, impressora, datashow e softwares de edição gráfica e/ou textual. O Quadro 1 apresenta, em detalhes, tais dados.

Quadro 1: Artigos elegíveis, ordenados por ano de publicação e autoria, com as respectivas MA e TDIC utilizadas

\begin{tabular}{|c|c|c|c|c|}
\hline Ano & Autor(es) & Título & $\begin{array}{c}\text { Metodologia } \\
\text { Ativa }\end{array}$ & TDICs \\
\hline 2018 & Silva et al. & $\begin{array}{l}\text { Tecnologias digitais e } \\
\text { metodologias ativas na escola: o } \\
\text { contributo do Kahoot para } \\
\text { gamificar a sala de aula }\end{array}$ & Gamificação & $\begin{array}{l}\text { - Celular } \\
\text { - Computador* } \\
\text { - Kahoot }{ }^{1}\end{array}$ \\
\hline 2019 & $\begin{array}{l}\text { Oechsler; } \\
\text { Manerich; } \\
\text { Silva }\end{array}$ & $\begin{array}{l}\text { A relação entre professor e aluno } \\
\text { no processo de produção de vídeo } \\
\text { em sala de aula }\end{array}$ & $\begin{array}{l}\text { Produção } \\
\text { autoral (vídeo) }\end{array}$ & $\begin{array}{l}\text { - Câmera digital } \\
\text { - Celular } \\
\text { - Computador } \\
\text { - Datashow } \\
\text { - Vyond e Animaker² } \\
\text { - Movie Maker e } \\
\text { Openshot }^{3}\end{array}$ \\
\hline 2019 & Oliveira & $\begin{array}{l}\text { Estratégia híbrida para o processo } \\
\text { ensino-aprendizagem baseada na } \\
\text { participação ativa e avaliações } \\
\text { integradas }\end{array}$ & Peer Instruction & $\begin{array}{l}\text { - Celular } \\
\text { - Computador } \\
\text { - Datashow } \\
\text { - Kahoot } \\
\text { - Notebook } \\
\text { - YouTube } \\
\text { - youtubestartend.com }\end{array}$ \\
\hline
\end{tabular}




\begin{tabular}{|c|c|c|c|c|}
\hline 2019 & $\begin{array}{l}\text { Pantoja; } \\
\text { Vieira; Hanan }\end{array}$ & $\begin{array}{l}\text { Produção de jornal acadêmico } \\
\text { para abordagem dos temas } \\
\text { reciclagem e preservação da água } \\
\text { no ensino médio técnico }\end{array}$ & $\begin{array}{l}\text { Produção } \\
\text { autoral (jornal } \\
\text { impresso) }\end{array}$ & $\begin{array}{l}\text { - Celular } \\
\text { - Computador* } \\
\text { - Impressora* } \\
\text { - Softwares de edição } \\
\text { gráfica e/ou de texto* }\end{array}$ \\
\hline 2019 & $\begin{array}{l}\text { Silva; Sales; } \\
\text { Castro }\end{array}$ & $\begin{array}{l}\text { Gamificação como estratégia de } \\
\text { aprendizagem ativa no ensino de } \\
\text { Física }\end{array}$ & Gamificação & $\begin{array}{l}\text { - Celular } \\
\text { - Computador } \\
\text { - Datashow* } \\
\text { - Kahoot } \\
\text { - PhET } \\
\text { - Moodle }\end{array}$ \\
\hline 2020 & $\begin{array}{l}\text { Esteves e } \\
\text { Araújo }\end{array}$ & $\begin{array}{l}\text { Aprender e ensinar design digital } \\
\text { no contexto da cibercultura: } \\
\text { experiência de ensino com } \\
\text { metodologias ativas }\end{array}$ & $\begin{array}{l}\text { Aprendizagem } \\
\text { baseada em } \\
\text { projetos }(\mathrm{ABPj})\end{array}$ & $\begin{array}{l}\text { - Apple Store e Google } \\
\text { Play }^{6} \\
\text { - Computador } \\
\text { - Invision } \\
\text { - Google Material } \\
\text { Design }^{8} \\
\end{array}$ \\
\hline
\end{tabular}

1 - Kahoot é plataforma online interativa que incorpora elementos utilizados no design dos jogos para engajar os usuários na aprendizagem. Fonte: http://periodicosnovo.ifsul.edu.br/index.php/thema/article/view/838/791. Acesso em: 05 de jul. de 2021.

2 - Vyond e Animaker são aplicativos de animação. Fonte: https://seer.ufrgs.br/renote/article/view/95951/53943. Acesso: 05 de jul. de 2021.

3 - Movie Maker e Openshot são softwares gratuitos de edição Fonte:

https://seer.ufrgs.br/renote/article/view/95951/53943. Acesso: 05 de jul. de 2021.

4 - youtubestartend.com é uma ferramenta online capaz de personalizar os vídeos do Youtube. Fonte: https://lume.ufrgs.br/handle/10183/200077. Acesso em: 05 de jul. de 2021.

5 - PhET é uma plataforma interativa de simulações de matemática e ciências gratuita, baseada numa extensiva pesquisa na educação e envolvimento dos alunos num intuitivo ambiente do gênero jogo, no qual os estudantes aprendem através da exploração e descoberta. Fonte: http://phet.colorado.edu/pt/. Acesso em: 10 de jun. 2021. 6 - Apple Store e Google Play são lojas virtuais de aplicativos. Fonte: https://www.rankmyapp.com/ptbr/mercado/diferencas-entre-app-store-e-google-play-store/. Acesso em 01 de jun. 2021.

7 - Invision é um software online que possibilita a criação de aplicativos navegáveis. Fonte: https://periodicos.claec.org/index.php/relacult/article/view/1750/1152. Acesso em: 05 de jul. de 2021. 8 - Google Material Design é um sistema com código de fonte aberto, adaptável de diretrizes, componentes e ferramentas que oferecem suporte às práticas de design de interface do usuário. Fonte: https://material.io/. Acesso em: 01 de jun. de 2021.

* - TDIC não citadas pelo(s) autor(es), mas presumivelmente utilizadas.

O computador já foi bastante explorado enquanto instrumento e meio de ensinoaprendizagem, deixando de ser apenas um facilitador de cálculos para armazenar softwares educacionais (VALENTE, 1998; GUERRA, 2000; VALENTE, 2005). Assim, ao abordar as TDIC nos métodos de ensino-aprendizagem, o computador é o instrumento base nem sempre citado nas metodologias dos estudos, evidenciando-se o uso de softwares específicos ou do processo metodológico. Nos estudos selecionados, por exemplo, o uso no computador não é mencionado por Silva et al. (2018), porém esse mostra uma planilha para conversão de notas e cita o Excel para elaboração de gráfico e mensuração de resultados. Pantoja, Vieira e Hanan, (2019) também não aborda o uso do computador, porém descreve que os vídeos, produzidos pelos alunos, foram vistos por toda a turma e, portanto, foi possível prever o uso de um computador associado a um equipamento datashow. Ressalta-se, portanto, que o computador é 
um artefato "aliado de valor inestimável" (SANCHO; HERNÁNDEZ, 2006, p. 21) para a educação.

De acordo com dados do ano 2019 divulgados pelo Centro Regional de Estudos para o Desenvolvimento da Sociedade da Informação (Cetic.br), o celular era o principal meio de acesso dos estudantes à internet e, por estarem presentes em diversos estratos sociais, têm proporcionado a democratização do acesso à rede, modificando os fluxos informacionais (FARDO, 2013) e transformando o comportamento dos alunos (SILVA; SALES, 2017).

As pesquisas de conteúdo por meio das TDIC substituem as visitas às bibliotecas, sendo realizadas de forma rápida e eficaz (SILVA, 2020). Contudo deve-se questionar sobre os aspectos éticos, associados a plágios (PIMENTA, 2016), além de considerar que o acesso à informação não garante o conhecimento (SANCHO; HERNÁNDEZ, 2006; SACCOL; SCHLEMMER; BARBOSA, 2011), podendo, inclusive, ser empecilhos uma vez que consomem o tempo nas chamadas "redes de procrastinação" (ALVES; VIEIRA, 2015; SILVA, 2020).

Mesmo que o uso dos celulares como recurso didático em de aula tenha aumentado, ainda há uma grande parcela dos professores que não fazem uso de nenhuma tecnologia (Cetic.br, 2019). Isso pode refletir uma restrição devido a uma "convenção social" (SACCOL; SCHLEMMER; BARBOSA, 2011) ou mesmo um despreparo dos professores que, engessados em metodologias tradicionais, não se apropriam de novas tecnologias (ALVES; VIEIRA, 2015). Os estudos selecionados neste trabalho corroboram com esta possibilidade, visto que, para aplicação das MA, o celular foi necessário em cinco dos seis estudos (83,3\%).

Em termos de softwares, o Kahoot foi utilizado em três dos seis estudos selecionados (50\%), sendo o uso em dois deles como ferramenta para a gamificação (SILVA et al., 2018; SILVA; SALES; CASTRO, 2019); em Oliveira (2019), é empregado para fornecer feedbacks imediatos. O Kahoot é uma plataforma online interativa que incorpora elementos utilizados no design dos jogos para engajar os usuários na aprendizagem (SILVA et al., 2018). Este software pode ser utilizado para quatro tipos de atividades: (i) Quizzes (questionários de múltipla escolha com correção automática); (ii) Discussion (onde é colocada uma única questão, com várias opções de resposta, sendo útil para registros sem interrupção da aula, ou em pós-palestra); (iii) Survey (opção utilizada para abordar um tema e fazer sondagem da turma, por meio de questionamentos rápidos); (iv) Jumble (similar ao Quiz, mas nesta os alunos são desafiados a colocar as respostas na ordem correta) (SILVA et al., 2018). 
Assim como o Kahoot, outros softwares educativos têm surgido como suporte básico para a prática pedagógica. Nessa perspectiva, as TDIC visam os possíveis ganhos durante os processos de planejamento, de ensino e de aprendizagem, bem como sua utilidade para a diversificação dos processos avaliativos, além da integração de elementos multimidiáticos como imagens, gráficos, textos, vídeos e áudios que possibilitam variar as linguagens utilizadas no processo de ensino-aprendizagem (SILVA, 2020).

Existem, ainda, situações, como o ensino remoto e o ensino à distância $(\mathrm{EaD})$, nas quais as TDIC são fundamentais. Contudo deve-se ter em mente que as tecnologias não são uma solução pronta e não podem limitar as propostas pedagógicas (SILVA, 2020). Segundo VieiraJúnior (2012), o uso da tecnologia sob uma perspectiva pouco científica e nem sempre planejada pode gerar insucesso. A melhoria no processo de ensino aprendizagem é consequência da forma como as TDIC são utilizadas (BARRETO, 2014). Nesse sentido, antes de qualquer proposta ser feita para o uso de TDIC, o professor deve ter domínio de suas ferramentas, possibilidades de uso e das contribuições para a aprendizagem do aluno (SILVA, 2020).

\subsection{METODOLOGIAS ATIVAS COM RECURSOS DAS TDIC NO ENSINO TÉCNICO INTEGRADO} AO MÉDIO

Nesta seção, serão descritos os seis estudos selecionados no processo metodológico por ordem cronológica, estando agrupados em subtópicos nos casos em que utilizaram a mesma MA, a partir de seus princípios básicos e, conforme o trabalho, as etapas, os procedimentos, o experimento, os principais resultados e as conclusões.

\subsubsection{GAMIFICAÇÃ̃o}

A gamificação consiste no "uso de elementos de design dos jogos em contextos fora dos jogos" (DETERDING et al., 2011, p. 9). Em termos de aprendizagem, Landers (2014, p. 757) definiu a gamificação como "o uso de elementos do jogo, incluindo linguagem de ação, avaliação, conflito/desafio, controle, ambiente, ficção de jogo, interação humana, imersão, e regras/objetivos, para facilitar a aprendizagem e os resultados relacionados." Como estratégia de ensino, a gamificação pode ser considerada uma MA quando o professor utiliza regras claras (contrato didático) com o objetivo de desafiar e estimular os estudantes a realizarem suas missões (tarefas) (SILVA et al., 2018).

Para uma aplicação efetiva da gamificação e o retorno positivo no processo de ensinoaprendizagem, são necessários o planejamento da atividade e um aprofundamento teórico 
(SILVA; SALES; CASTRO, 2019). A teoria da gamificação prevê uma alteração direta em comportamentos e atitudes importantes para a aprendizagem, os quais devem afetar a relação entre o conteúdo instrucional e os resultados de aprendizagem, por meio de moderação ou mediação (LANDERS, 2014). Contudo esta teoria indica que os efeitos sobre a aprendizagem são positivos indiretos, não especificando quais os mecanismos devam ser acionados pelos elementos de design dos jogos (SAILER; HOMNER, 2020).

Em relação ao uso de TDIC na gamificação, pode-se dizer que elas não são um requisito para implementar a MA em sala de aula (DETERDING et al., 2011; FARDO, 2013). Contudo o uso das TDIC potencializa a gamificação através dos seus recursos (FARDO, 2013), fornecendo feedbacks imediatos, facilitando a execução de tarefas colaborativas e proporcionando flexibilidade de horário para os alunos (SALES et al., 2017). Neste trabalho, foram selecionados dois estudos que fizeram uso da gamificação no EMI, ambos por meio do software Kahoot (Quadro 1).

No primeiro estudo, Silva et al. (2018) buscam descrever as contribuições deste software para a gamificação em sala de aula por meio de um estudo de caso com uma turma do $4^{\text {o }}$ semestre do EMI em Química, do Instituto Federal de Educação Ciência e Tecnologia do Ceará (IFCE), em um período de 16 semanas. O Kahoot foi utilizado na modalidade Quizzes, sendo metodologia dividida em três etapas: (i) definição das regras (contrato didático): etapa em que os alunos foram esclarecidos sobre as suas missões (tarefas), o tempo de execução e os objetivos da atividade; (ii) ensino do conteúdo (etapa foi realizada em fases nas quais cinco conteúdos específicos do tema Óptica Geométrica foram trabalhados em aula e os alunos foram divididos em cinco grupos que deveriam responder aos Quizzes para avaliar o conhecimento prévio); e (iii) avaliação: realizada por feedback automático do Kahoot.

De acordo com observações dos autores, o Kahoot, ao fornecer feedbacks imediatos, pode promover reflexões sobre o aprendizado, especialmente quanto à contabilização de tempo que a equipe levou para resolver os problemas. Quanto à gamificação, ainda de acordo com os autores, o software contribuiu ao estabelecer regras claras, feedbacks imediatos, pontuação por acerto, competição entre alunos/equipes, além de proporcionar prazer e diversão durante o processo de ensino-aprendizagem.

O segundo trabalho foi produzido por Silva, Sales e Castro (2019) e apresenta um estudo quase-experimental envolvendo grupo controle (GC) e grupo experimental (GE). O objetivo foi investigar os resultados do ganho de aprendizagem em aulas de Física proporcionado pela 
gamificação, por meio do teste de Hake. O estudo foi realizado com 49 alunos de duas turmas do $2^{\circ}$ ano do EMI do IFCE, os quais fizeram um pré-teste e um pós-teste. O GC, composto por 33 alunos do curso técnico integrado em informática, teve aulas tradicionais expositivas. O GE, formado por 16 alunos do curso técnico integrado em eletrotécnica, teve aulas gamificadas, com a sala de aula organizada em 'ilhas de aprendizagem' e os alunos separados em grupos.

A sequência didática proposta pelos autores está organizada em sete fases: (i) definição de tópicos específicos e o contrato didático, sendo estabelecido a realização de quizzez online, via Kahoot ao final de cada tópico no qual a pontuação foi maior conforme a complexidade da atividade; (ii) verificação os conhecimentos prévios dos alunos, por meio de Quiz disponível no Kahoot; (iii) Proposição de situações-problema iniciais de nível básico no qual, a partir de situações do cotidiano, os alunos responderam a questionários; (iv) Proposição de situaçõesproblema de nível intermediário, por meio de simuladores ancorados na plataforma PhET; $(v)$ Proposição situações-problema de nível avançado em que aulas foram ministradas no laboratório de Física; (vi) Avaliação, com realização de prova e quizzes divididos em três níveis de complexidade (básico, intermediário e avançado), de acordo com a complexidade para se resolver a situação-problema. A missão do aluno era conquistar 10.000 pontos em até 60 minutos, cabendo a ele escolher quais questões iria responder, respeitando, assim, o seu ritmo e estilo de aprendizagem; e (vii) Realização de encontro final integrador, organizado para a revisão de conteúdo e discussão sobre os questionários aplicados.

Os autores verificaram ausência de diferenças estatísticas, entre GC e GE, na ocasião de aplicação do pré-teste por meio do teste $U$ de Mann-Whitney. Mas, no pós-teste, as diferenças foram significativas e apontaram maior desempenho de GE. Para mensurar o ganho de aprendizagem em ambas as metodologias de ensino (gamificação e tradicional), Silva, Sales e Castro (2019) realizaram um teste de ganho normatizado (Equação 1), conforme proposto por Hake (1998) o qual vem sendo utilizado em pesquisas envolvendo MA no ensino de Física, segundo os autores.

$$
g=\frac{\% \text { pos }-\% \text { pre }}{100 \%-\% \text { pre }}
$$

Onde $g$ é o ganho normatizado; \%pós = porcentagem de acerto do pós-teste, aplicado após a implementação da metodologia; \%pré = porcentagem de acerto do pré-teste, aplicado antes da intervenção; e 100\% é a porcentagem máxima de acertos possível. 
A partir dos resultados, os autores concluíram que os alunos que tiveram aulas gamificadas obtiveram um ganho de aprendizagem $(g=0,38)$ superior aos alunos que tiveram aulas tradicionais $(\mathrm{g}=0,11)$.

\subsubsection{Produção Autoral}

A produção autoral (PA) de vídeos ou jornais pelos próprios alunos tem sido amplamente utilizada, especialmente no ensino básico (MACIEL, 2019), sendo abordada sob diferentes aspectos. Em alguns estudos, a PA aparece associada a alguma MA, como a ABP (ARAÚJO et al., 2017) e a sala de aula invertida (ALBINO, 2020). Em outros, tem sido citada como recurso didático-pedagógico facilitador do ensino-aprendizagem (XIMENES; SANTANA, 2021), e, na maioria dos trabalhos, são relatados apenas os resultados obtidos com essa metodologia (SOUSA, 2015; COSTA, 2017; BERALDO, 2020).

Contudo a PA pode ser considerada uma MA. Na PA, visando o processo de ensinoaprendizagem, o aluno é o protagonista da construção do conhecimento (SOUSA, 2015; COSTA, 2017; OECHSLER; MANERICH; SILVA, 2019; BERALDO, 2020), a partir da orientação do professor (OECHSLER; MANERICH; SILVA, 2019; BERALDO, 2020). Segundo Costa (2017), a PA possibilita a criação independente e com foco nos interesses dos próprios alunos, ao mesmo tempo que aborda os conteúdos discutidos nos espaços educativos. Neste processo, os alunos contextualizam o conhecimento formal com as atividades do seu cotidiano (BERALDO, 2020), o que tem sido amplamente discutido e constitui uma das "facetas da chamada aprendizagem significativa" (SOUSA, 2015, p. 145). Nesse sentido, Mallmann e Jorge (2019) abordaram a PA de videoaulas como metodologia particip(ativa), enquanto Maciel (2019) elaborou e validou a videoaprendizagem, uma MA com foco nos processos de criação de vídeos de bolso.

Em termos das TDIC na PA, Beraldo (2020) relatou facilidade para coleta de informações, como em coberturas de eventos e entrevistas, além da facilidade na manutenção do jornal eletrônico, sempre atualizado. Para Laranjeira et al. (2019), as mídias são importantes para a informação crítica e a construção do conhecimento colaborativo com os educandos. A partir do processo metodológico, foram selecionados dois estudos que fizeram uso da produção autoral, com uso de TDIC no EMI.

No primeiro deles, Oechsler, Manerich e Silva (2019) investigaram a relação entre professor e aluno em aulas direcionadas para a produção de vídeos. A pesquisa foi desenvolvida com três turmas do EMI, em Química e Informática, do Instituto Federal de Santa Catarina 
(IFSC) Campus Gaspar, na unidade curricular de Matemática. A metodologia de produção de vídeos em sala de aula foi realizada em grupo nas seguintes etapas: (i) conversa com alunos e apresentação de tipos de vídeos; (ii) escolha e pesquisa do tema para a produção de vídeos; (iii) elaboração do roteiro; (iv) gravação das cenas; $(v)$ edição das imagens; e (vi) divulgação dos vídeos para a própria turma.

Os alunos gravaram as imagens com câmeras digitais ou de celular, utilizaram aplicativos de animação (Vyond e Animaker) e editaram as cenas em softwares gratuitos de edição instalado nos computadores da escola (Movie Maker e Openshot). Segundo os autores, em cada uma das etapas da PA, o aluno atuou como protagonista, decidindo a forma como o vídeo seria produzido e o conteúdo explorado, enquanto coube à professora o papel de mediadora, incentivando o diálogo e a reflexão do grupo para resolver o problema. Neste processo, a professora utilizou seu conhecimento para estimular os alunos a produzir conhecimento. Ademais, os autores destacaram que pôde ser observada troca de saberes, em que o professor produziu conhecimento tecnológico e os alunos conhecimento matemático, provendo, portanto, o "diálogo horizontal” freireano (OECHSLER; MANERICH; SILVA, 2019).

O segundo trabalho foi conduzido por Pantoja, Vieira e Hanan, (2019). Os autores utilizaram a PA de jornais, com os objetivos de relacionar o cotidiano dos alunos com temas da área de Química Ambiental e incentivar a prática da leitura e da escrita científica. O trabalho foi realizado em duas turmas, com 44 e 36 alunos, durante o andamento das disciplinas de Fundamentos de Laboratório ( $1^{\circ}$ ano) e Métodos Analíticos Qualitativos e Quantitativos ( $2^{\circ}$ ano), do EMI em Biotecnologia do Instituto Federal do Acre (IFAC), Campus Xapuri. A metodologia consistiu em quatro etapas:

I. delimitação dos temas;

II. divisão das equipes de alunos (repórteres, repórteres da comunidade, editores, editores de lazer e diagramadores);

III. produção, ficando cada grupo responsável por uma atividade: a) repórteres buscaram conteúdos sobre o tema de seus jornais em instituições públicas ou comerciais e em escolas; b) repórteres da comunidade buscaram conteúdo em entrevistas com famílias e/ou alunos da escola; $c$ ) editores produziram matérias com aspectos científicos dos temas (caráter acadêmico); $d$ ) editores de lazer elaboraram curiosidades, palavras cruzadas, tirinhas $\mathrm{e}$ 
desenhos sobre os temas; e $e$ ) diagramadores ficaram responsáveis pela edição, escolha do melhor layout, pela distribuição das seções e conteúdos;

IV. distribuição, em que os jornais foram entregues aos participantes do II Congresso de Ciência e Tecnologia do Instituto Federal do Acre - Campus Xapuri (2017); e

V. Questionário, onde os alunos responderam a seis perguntas objetivas e uma subjetiva, relacionadas às suas impressões sobre o trabalho desenvolvido.

Os autores descreveram as atividades realizadas, evidenciando diferentes comportamentos dos grupos: os repórteres foram incentivados por um jornalismo investigativo, os editores perceberam a possibilidade de contextualização de termos de química orgânica com outros temas e os editores de lazer apresentaram o conteúdo de forma lúdica e interativa; não houve comentários acerca de observações do trabalho dos diagramadores. Segundo os autores, os alunos, de modo geral, realizaram debates sobre os temas durante a realização das atividades, além de expressarem a importância de a comunidade local receber as informações, o que trouxe maior comprometimento com o trabalho. Em termos da percepção dos alunos, obtida por meio do questionário, o trabalho aponta que a participação deles na produção do jornal facilitou o aprendizado, aumentou seus saberes e estimulou a participação de todos para que todas as etapas fossem cumpridas. Além disso, os alunos disseram não terem sentido falta da metodologia tradicional para complementar o conteúdo.

Os autores relataram resultados positivos na etapa de distribuição, sendo descritos leitores interagindo com o conteúdo e dando feedbacks importantes, como o ineditismo das notícias. O maior estímulo e a participação efetiva dos alunos podem, segundo os autores, ser explicadas pelas escolhas colegiadas dos alunos em seus grupos: aqueles com perfil investigativo fizeram parte do grupo de repórteres, aqueles que gostavam de escrever compuseram o grupo dos editores, quem gostava de desenhar escolheu o grupo de editores de lazer, enquanto os que possuíam maior afinidade com a informática integraram o grupo dos diagramadores. Embora os autores não tenham discutido essa divisão quanto ao perfil do aluno, o relato trazido no trabalho possibilita vincular o exposto ao estilo de aprendizagem dos alunos (VIEIRA JUNIOR, 2012).

\subsubsection{PEER INSTRUCTION}

O Peer Instruction (PI) ou instrução entre pares é um tipo de metodologia ativa (KNIGHT; BRAME, 2018) usada para inversão da sala de aula (SCHMITZ, 2016), onde os alunos se apropriam do conteúdo em casa e, em de sala de aula, realizam trabalhos pertinentes 
ao conteúdo (PEREIRA; SILVA, 2018). No PI, o estudo em casa deve consistir em pequenos textos acompanhados por tarefas de leitura (TL) que são questões conceituais objetivas (KIELT, 2017). Em sala de aula, o professor faz uma pergunta com opções de respostas discretas, o chamado teste conceitual (TC). Os alunos então refletem, resolvem e respondem individualmente, sendo as respostas registradas pelo professor. Em seguida, os discentes discutem com os colegas, explicando o seu raciocínio, e apontam a resposta tida como correta novamente (CROUCH; MAZUR, 2001). Durante o processo, o professor deve conduzir a discussão, incentivando o raciocínio e motivando os grupos (TURPEN; FINKELSTEIN, 2010; ZINGARO; PORTER, 2014). A depender do percentual de acertos, o professor deve retomar o conteúdo e/ou refazer os grupos de discussão, em caso de baixo índice de acertos, ou fazer breves comentários e prosseguir para outro TC (ARAUJO; MAZUR, 2013; OLIVEIRA; VEIT; ARAÚJO, 2015).

O ciclo do PI oferece oportunidades para todos os elementos necessários para a aprendizagem cooperativa (KNIGHT; BRAME, 2018), segundo a teoria da interdependência social (JONHSON; JONHSON, 2009). De acordo com Tullis e Goldstone (2020), a discussão aos pares pode promover processos metacognitivos de revisão dos modelos mentais, onde os alunos monitoram sua compreensão e refletem sobre mal-entendidos (MCDONNELL; MULLALLY, 2016).

Quanto ao uso das TDIC, embora estas não sejam essenciais para a implementação do PI, o seu uso pedagógico adequado pode trazer benefícios. A utilização de um sistema eletrônico de votação, por exemplo, possibilita rápido envio e contagem de votos, além de permitir o arquivamento dos dados, o feedback automático e a disponibilização de gráficos com os resultados das respostas (KIELT, 2017). Esse sistema também possibilita a votação anônima que, embora não afete a aprendizagem, é preferida pelos alunos (KNIGHT; BRAME, 2018). $\mathrm{Na}$ revisão sistemática deste trabalho, encontrou-se apenas um estudo que fez uso da metodologia PI; trata-se da tese de doutorado de Oliveira (2019).

Em sua pesquisa, a autora teve por objetivo construir uma estratégia híbrida para o processo de ensino-aprendizagem, por meio do PI e a rotação de estações, baseada nos princípios da Teoria de Bruner, com vistas a melhorar a participação e potencializar o desempenho dos estudantes do EMI. O estudo foi desenvolvido com 164 alunos, novatos e veteranos, matriculados em turmas do curso Técnico em Informática, modalidade integrado, do Instituto Federal Farroupilha (IFFar), Campus Júlio de Castilhos. O estudo envolveu cinco 
disciplinas dos núcleos técnico e básico e teve duração de três anos. Foram desenvolvidos estudos piloto e o experimento final. Nos estudos piloto, identificou-se lacunas da investigação e planejadas novas experimentações. Os experimentos finais foram realizados no período de abril a julho de 2018, tendo foco nas disciplinas de Química (duas turmas) e Programação I (quatro turmas), com duração de quatro e três semanas, respectivamente.

Os experimentos foram cruzados, pois os mesmos 57 alunos participaram de ambos, sendo a divisão, em turmas, realizada de forma aleatória. No experimento de Química, Oliveira (2019) comparou o PI "tradicional” com o PI acrescido da rotação de estações (ensino híbrido), em que, ao invés de os alunos acessarem o conteúdo em casa, eles acessam em sala de aula de forma online. O PI "tradicional" foi realizado da seguinte forma: (i) disponibilização, via Moodle, do conteúdo para estudo em casa, sendo este formado por vídeos do Youtube editados, além de simulações da plataforma PhET; (ii) retomada breve do conteúdo, pelo professor; (iii) votação individual pelo Kahoot; (iv) discussão colaborativa; (v) nova votação; e (vi) explanação final. Esse fluxo foi alterado conforme o percentual de acertos, sendo retomado o conteúdo e ocorrendo uma terceira votação.

O PI + rotação de estações consistiu em dividir a aula em dois momentos: (1) alunos acessaram individualmente o conteúdo online; e (2) condução das demais etapas do (PI). No experimento com a disciplina de Programação I, foram comparados: (i) PI + rotação de estações (E1); (ii) PI “tradicional” (E2); (iii) PI + rotação de estações, com a rotação livre, ou seja, o aluno que finalizou a atividade individual online pôde seguir para as próximas estações (discussão colaborativa ou estação avaliativa, onde respondem à questão do PI) (E3); e (iv) método tradicional, que consistiu em aulas expositivas (MT).

Os ganhos de aprendizagem entre as metodologias foram comparados através de pré e pós-testes de Mann-Whitney e de Kruskal-Wallis (análise por pares). A autora também realizou um questionário para os alunos opinarem, anonimamente, sobre os métodos experienciados e acerca de sua participação em aula (autoavaliação).

Segundo Oliveira (2019), o PI com rotação de estações (método E1) promoveu maior ganho de aprendizagem, sendo ainda superior se a rotação for livre (método E3). Nesses métodos, E3 e E1, a autora também observou discussões mais engajadas do que no PI “tradicional”, possivelmente devido ao baixo acesso ao conteúdo durante o estudo em casa. Os menores desempenhos foram observados na metodologia tradicional (MT), onde o estudante é mais espectador do que atuante. De acordo com a autora, embora todos os alunos tenham 
realizado exercícios, a forma como o conteúdo chega ao discente é o que influencia, de fato, sua efetiva aprendizagem. "Os momentos que oportunizam a autorregulação, a partir do feedback imediato, fortalecem toda a sequência didática promovida pela Estratégia Híbrida" (OLIVEIRA, 2019, p. 152). A autora ainda destacou que o método proposto com uso do ensino híbrido, ao ser iniciado pela estação individual, passando posteriormente pela estação colaborativa, pode otimizar a aprendizagem.

Outro resultado importante para a autora, sendo inclusive destacado por ela como "ponto alto", foi o uso do Kahoot que, ao possibilitar o feedback imediato, em especial com a geração dos rankings dos acertos, proporcionou uma maior participação discente nas discussões, inclusive com disputa entre os estudantes, mesmo sem a atribuição de nota. Em relação à opinião dos alunos, os resultados foram ao encontro dos resultados obtidos na avaliação de desempenho, sendo E3 o método preferido.

Em suas considerações finais, Oliveira (2019) destacou os melhores resultados das atividades de estudo supervisionadas, especialmente para alunos do primeiro ano. Nesse sentido, a autora propôs o uso dos celulares como ferramenta pedagógica, ao contrário do que vigorava na instituição. Ressaltou também a existência de diversas ferramentas e recursos educacionais gratuitos, ainda pouco utilizados na sala de aula, muitas vezes por desconhecimento dos docentes que impactam diretamente na organização didática das aulas.

\subsubsection{APRENDIZAGEM BASEADA EM PROJETOS}

A aprendizagem baseada em projetos (ABPj) trabalha com problemas reais, buscando por soluções que exigem a aplicação da teoria na prática (SOUZA et al., 2017). É uma MA que envolve diversas disciplinas ou áreas do conhecimento (CORREIA; OLIVEIRA, 2020), além de exigir mais tempo para solução completa (SANTANA, 2009; LENZ; WELLS; KINGSTON, 2015). Para Chen e Yang (2019), ela é um método de ensino-aprendizagem sistemático baseado no construtivismo.

A ABPj se inicia com problemas mal estruturados (SARAVERY, 2006), o que permite ao aluno a exploração de diversas alternativas, ficando o professor com o papel de facilitador e treinador e, à medida que novas informações são encontradas, as soluções podem mudar continuamente (OGUZ-UNVER; ARABACIOGLU, 2014). A ABPj requere dos alunos conhecimentos prévios e habilidades, como a observação e a investigação (MILLS; TREAGUST, 2003), a alfabetização científica (OGUZ-UNVER; ARABACIOGLU, 2014) e as estratégias metacognitivas (MILLS; TREAGUST, 2003) e de raciocínio (HMELO-SILVER; 
DUNCAN; CHINN, 2006). Segundo Mills e Treagust (2003), o sucesso da ABPj exige também habilidades de trabalho em equipe e comunicação, estas podendo ser desenvolvidas durante a própria MA (SANTANA, 2009).

Para a ABPj, as TDIC têm sido fundamentais, inclusive sendo uma MA recomendada por acomodar as mudanças e atualizações tecnológicas (BENDER, 2012; SILVA et al., 2018). Segundo Chen e Yang (2019), os efeitos positivos da ABPj sobre o desempenho acadêmico, em comparação com o ensino tradicional, entre outros fatores, dependem da tecnologia de informação utilizada como suporte para esta MA. Na ABPj, as TDIC podem ser parte integrante do projeto, tais como softwares, interfaces gráficas, robótica, dentre outras possibilidades (CORINO; BERTAGNOLLI, 2018; ESTEVES; ARAÚJO, 2020), além de serem requeridas para a resolução dos problemas inerentes aos projetos (SILVA et al., 2018; ESTEVES; ARAÚJO, 2020; GIORDANO et al., 2020). Na revisão para este trabalho, apenas um estudo com ABPj aplicada ao EMI, com uso de TDIC, foi selecionado (ESTEVES; ARAÚJO, 2020).

No estudo conduzido por Esteves e Araújo (2020), apresentou-se um relato de experiência de ensino em ABPj com alunos do sexto semestre do EMI em Comunicação Visual, do Instituto Federal Sul-rio-grandense (IFSul). A pesquisa durou oito semanas e os estudantes desenvolveram atividades individualmente, em duplas ou trios, criando interfaces gráficas para aplicativos. A experiência de ensino envolveu duas disciplinas obrigatórias (Metodologia do Projeto e Informática II) e a temática foi escolhida pelos próprios alunos.

Inicialmente, os autores introduziram o conteúdo por meio de aulas expositivas e dialogadas, com momentos para as análises de interfaces gráficas. Para a criação dos projetos, os autores utilizaram a metodologia centrada no usuário (DCU), dividindo-a em quatro etapas: (i) identificação dos requisitos: etapa em que os alunos analisaram, por exemplo, o público-alvo e a motivação para desenvolver o app (aplicativo), além de analisarem os apps concorrentes encontrados no Apple e Google Store; (ii) criação soluções alternativas: envolveu entrevistas com possíveis usuários, criação de storyboards ${ }^{1}$ e definição de proto-personas ${ }^{2}$, com o objetivo de refinar a ideia inicial do app; (iii) construção de protótipos testáveis: etapa em que os estudantes simularam as telas dos apps em papel (rabiscoframes) que foram construídas no

\footnotetext{
1 “[...] sequência em quadrinhos utilizada no cinema, em que o processo consiste na organização de uma série de painéis ilustrados para representar o fluxo de uma cena" (ESTEVES; ARAÚJO, 2020, p. 7).

2 “Para Gothelf (2013), as proto-personas são baseadas em suposições e hipóteses, ajudando a definir quem irá utilizar o produto e por que fará o uso dele" (ESTEVES; ARAÚJO, 2020, p. 7).
} 
Google Material Design, sendo o protótipo navegável elaborado no software online Invision; e (iv) avaliação com usuários: etapa onde os alunos conduziram testes de usabilidade, com base no método Think-Aloud, e procederam melhorias no projeto. Ao fim da proposta, foram criados apps classificados em cinco categorias, conforme o objetivo principal e a missão de cada projeto: comercial, comunicação, conscientização, entretenimento e jogos.

Segundo os autores, os apps atenderam aos requisitos de design para dispositivos móveis e apresentaram temas relacionados ao cotidiano dos estudantes. Em termos de aprendizagem, Esteves e Araújo (2020) destacaram que o desenvolvimento da metodologia $\mathrm{DCU}$, associada à $\mathrm{ABPj}$, possibilitou auxílio mútuo entre os alunos, que se apropriaram de conhecimentos além do proposto na disciplina de Metodologia de Projeto. Os autores relataram também que a escolha livre do tema foi essencial para motivar os discentes, tendo sido observado que eles se mostraram satisfeitos e orgulhosos dos projetos desenvolvidos, manifestando interesse de aprofundar os estudos na área de design de interfaces e design de interação.

\section{CONSIDERAÇÕES FINAIS}

Os Institutos Federais de Ciência e Tecnologia (IF) trazem, em suas concepções e princípios, mudanças do ensino tradicional requeridas nos Parâmetros Curriculares Nacionais (PCN) do Ensino Médio (BRASIL, 2000; BRASIL, 2002), trabalhando a proposta de exercícios curriculares que utilizem os princípios da interdisciplinaridade e da aprendizagem contextualizada. Na proposta de Ensino Médio Integrado (EMI) trabalhada pelos IF, é imprescindível a participação ativa do aluno, tomando-o como um sujeito do processo educacional e com capacidade de gerar conhecimento a partir da interação com a realidade (BRASIL, 2010).

Esses princípios, conforme abordado nesta revisão, são exercitados quando o professor que leciona no EMI adota as MA. Entretanto, a aplicação da MA nos IF ainda pode ser percebida em caráter experimental. Na maioria dos trabalhos apresentados neste estudo de revisão bibliográfica, as MA foram apresentadas como uma substituição à metodologia tradicional. Apenas Oliveira (2019) descreveu uma possível melhoria de uma MA, embora essa ainda não fosse utilizada pelos professores, os quais conduziam as aulas por métodos tradicionais (aulas expositivas).

Portanto, percebe-se que, ainda que a organização curricular dos IF possibilite "buscar metodologias que melhor se apliquem a cada ação, estabelecendo a indissociabilidade entre 
ensino, pesquisa e extensão" (BRASIL 2010, p. 27), os resultados encontrados neste estudo não diferem daqueles citados por outros autores em diversos níveis e modalidades educacionais (ARAGÃO; MARANHÃO, 2019; SANTOS et al. 2020). Assim, ao final desta pesquisa, podese afirmar que, até o presente momento, os professores lotados nos IF ainda não se apropriaram da MA em suas práticas cotidianas.

A maior parte dos trabalhos que compuseram o corpus desta pesquisa foi composta por estudos que não utilizaram parâmetros para mensurar os resultados, sendo pautados em observações dos próprios autores ou por meio da coleta de entendimentos junto aos alunos envolvidos. Entendemos ser importante mensurar os benefícios da aprendizagem e a avaliação da efetividade das metodologias de ensino-aprendizagem, além de serem indispensáveis para nortear as tomadas de decisão. Aqueles estudos que mensuraram os ganhos de aprendizagem utilizaram pré e pós-testes, os quais não são capazes de detectar o nível de conhecimento adquirido pelos alunos. Nesse sentido, recomenda-se a leitura de Nunes (2019). Em sua dissertação de mestrado, o autor propôs um método baseado na Taxonomia de Bloom, que quantifica percentualmente e classifica a aprendizagem dos alunos.

O uso das TDIC foram fundamentais para a execução de todas as MA citadas. Contudo esta pesquisa indica que os professores podem não estar familiarizados com algumas tecnologias e ferramentas educacionais, muitas delas de acesso livre. Nesse sentido, destaca-se a necessidade de fomentar ações de formação docente voltadas para o trabalho com as novas metodologias. Ressalta-se aqui a contribuição trazida pela pesquisa desenvolvida por Oechsler, Manerich e Silva (2019), em que, durante a produção autoral de vídeos, houve um círculo de aprendizagens entre professores e alunos, freireanamente.

Por fim, o mapeamento da bibliografia exposta neste estudo deixou evidente que as MA atendem a outras orientações do PCN e dos objetivos dos IF (BRASIL, 2000; BRASIL, 2010). As MA podem possibilitar uma formação humana mais ampla, promovendo o desenvolvimento de habilidades e competências, tais como trabalho em equipe e a comunicação, além de promoverem a extensão de conhecimentos técnicos e científicos à comunidade. Ademais, possíveis trabalhos futuros, que envolvam a aplicação de metodologias para avaliação do ganho de aprendizagem, em MA por meio de TDIC, são de grande relevância. Esta demanda surge a partir da carência desta informação nos estudos mapeados, sendo este um dos pontos de maior dificuldade tanto na análise quanto na seleção do método de ensino-aprendizagem. 


\section{REFERÊNCIAS}

ABDULLAYEV, Abdukayum Abdulkhayevich. System of information and communication technologies in the education. Science and World, v. 5, n. 81, p. 19-21, 2020.

ALBINO, Marcel Sérgio. Sala de Aula Invertida em um colégio do interior paulista. In: FERREIRA, Emerson Benedito; LOPES, Mario Marcos. Pesquisas em educação: cidadania, ensino e sociedade. São Carlos: Pedro \& João, 2020. p. 93-111.

ALVES, Eliane Dias Gomes; VIEIRA, Márcia de Freitas. Celular e sala de aula: dos limites às possibilidades. In: WORKSHOP DE INFORMÁTICA NA ESCOLA, 21, 2015, Maceió. Anais... Maceió: Sociedade Brasileira de Computação, 2015. p. 236-

245. http://dx.doi.org/10.5753/cbie.wie.2015.236

ARAGÃO, Enéias; MARANHÃO, Rúbiu Vilar. Estudos sobre o uso da metodologia ativa no ensino superior do Brasil: uma revisão bibliográfica. Revista Ciências da Saúde e

Educação, v. 1, n. 2, p. 1-15, 2019. Disponível em:

https://revista.iesgo.edu.br/ojs/index.php/CSEI/article/view/28/10. Acesso em: 05 de jul. de 2021.

ARAÚJO, Sérgio Ricardo Fernandes de; RODRIGUES NETO, João Firmino; MACIEL, Michelline do Vale; VELEDA, André Matheus de Souza; ROCHA, Lara Valeska de Medeiros. Produção de vídeo educacional: modelo interativo usando o PBL. Revista de Saúde Digital e Tecnologias Educacionais, v. 2, n. 3, p. 51-58, 2017. Disponível em: http://periodicos.ufc.br/resdite/article/view/20192/97428. Acesso em: 05 de jul. de 2021.

ARAUJO, Ives Solano; MAZUR, Eric. Instrução pelos colegas e ensino sob medida: uma proposta para o engajamento dos alunos no processo de ensino-aprendizagem de Física. Caderno Brasileiro de Ensino de Física, v. 30, n. 2, p. 362-384, 2013. https://doi.org/10.5007/2175-7941.2013v30n2p362

ÁVILA, Ricardo Lima Feitosa de; SOARES, José Marques. Concepção de ferramenta de apoio à correção de questões dissertativas com base na adaptação de algoritmos de comparação e busca textual combinados com técnicas de pré-processamento de textos.

Revista Novas Tecnologias na Educação, v. 10, n. 3, p 1-11, 2012. https://doi.org/10.22456/1679-1916.36439

BARRETO, Flávio Chame. Informática descomplicada para educação: aplicações práticas para sala de aula. São Paulo: Érica, 2014.

BASÍLIO, Edvar Ferreira; OLIVEIRA, Diana Nara da Silva; RABELO, Maria Vanessa Maia; RIBEIRO, Luís Távora Furtado; LIMA, Carlos Rochester Ferreira; SAMPAIO, Perpétua Socorro Lopes; MARCOS, Adriana Isabel Rodrigues; GUIMARÃES, Marília Duarte.

Tecnologias digitais de informação e comunicação (TDIC) numa perspectiva interdisciplinar no ensino de geografia: uma análise socioespacial de Limoeiro do Norte-Ceará. Research, Society and Development, v. 9, n. 11, p. e86091110525-e86091110525, 2020.

http://dx.doi.org/10.33448/rsd-v9i11.10525

BENDER, William N. Project based learning: differentiating instruction for the 21 st century. 1. ed. Thousand oaks: Corwin Publishers, 2012. Tradução de: RODRIGUES, 
Fernando de Siqueira. Porto Alegre: Penso, 2015. Resenha de: CIPOLLA, Luiz Eduardo. Aprendizagem baseada em projetos: a educação diferenciada para o século XXI. Administração: ensino e pesquisa, v. 17, n. 3, p. 567-585, 2016. https://doi.org/10.13058/raep.2016.v17n3.440

BERALDO, Patrícia. Mídia digital: produção de jornal eletrônico escolar. In: CONGRESSO BRASILEIRO DE CIÊNCIAS DA COMUNICAÇÃO, 43, 2020, Online. Anais... Evento Online: Intercom - Sociedade Brasileira de Estudos Interdisciplinares da Comunicação, online, 2020. p. 1-14. Disponível em:

https://portalintercom.org.br/anais/nacional2020/resumos/R15-1058-1.pdf. Acesso em: 05 de jul. de 2021.

BRASIL. Secretaria de Educação Básica. PCN Ensino Médio: ciências da natureza, matemática e suas tecnologias. Brasília: Ministério da Educação, 2000. Disponível em: http://portal.mec.gov.br/seb/arquivos/pdf/ciencian.pdf. Acesso em: 05 de jul. de 2021.

BRASIL. Secretaria de Educação Básica. PCN+ Ensino Médio: orientações educacionais complementares aos Parâmetros Curriculares Nacionais: ciências da natureza, matemática e suas tecnologias. Brasília: Ministério da Educação, 2002. Disponível em:

http://portal.mec.gov.br/seb/arquivos/pdf/CienciasNatureza.pdf. Acesso em: 05 de jul. de 2021.

BRASIL. Secretaria de Educação Profissional e Tecnológica. Um novo modelo de educação profissional e tecnológica: concepções e diretrizes. Brasília: Ministério da Educação, 2010. Disponível em:

http://portal.mec.gov.br/index.php?option=com docman\&view=download\&alias=6691-ifconcepcaoediretrizes\&Itemid=30192. Acesso em: 05 de jul. de 2021.

CENTRO REGIONAL DE ESTUDOS PARA DESENVOLVIMENTO DA SOCIEDADE DA INFORMAÇÃO (Cetic.br). Pesquisa sobre o uso das tecnologias de informação e comunicação nas escolas brasileiras: TIC educação. São Paulo: Núcleo de Informação e Coordenação do Ponto BR, Comitê Gestor da Internet no Brasil, 2019. Disponível em: https://cetic.br/media/docs/publicacoes/216410120191105/tic_edu_2018_livro_eletronico.pdf . Acesso em: 05 de jul. de 2021.

CHEN, Cheng-Huan; YANG, Yong-Cih. Revisiting the effects of project-based learning on students academic achievement: a meta-analysis investigating moderators. Educational Research Review, v. 26, p. 71-81, 2019. https://doi.org/10.1016/j.edurev.2018.11.001

COSTA, Sueller Oliveira da. A autoria em sala de aula: o incentivo à participação discente e docente por meio de projetos que envolvem a produção midiática para a Educação. In: CONGRESSO BRASILEIRO DE CIÊNCIAS DA COMUNICAÇÃO, 40, 2017, Curitiba. Anais... Evento Online: Intercom - Sociedade Brasileira de Estudos Interdisciplinares da Comunicação, online, 2017. p. 1-15. Disponível em:

https://portalintercom.org.br/anais/nacional2017/resumos/R12-2284-1.pdf. Acesso em: 05 de jul. de 2021.

CORINO, Marcos Juares Vissoto; BERTAGNOLLI, Silvia de Castro. Robótica educacional como ferramenta pedagógica para ensinar os conceitos básicos de hardware de computadores. 
In: MOSTRA NACIONAL DE ROBÓTICA, 8, 2018, João Pessoa. Anais... Sorocaba: UNESP, 2018. p. 693-697. Disponível em: http://sistemaolimpo.org/midias/uploads/5d91f35954d0644f3dffc7ad52c958d1.pdf. Acesso em: 05 de jul. de 2021.

CORREIA, Waydja Cybelli Cavalcanti; OLIVEIRA, Gilvaneide Ferreira. Reflexões sobre a prática da interdisciplinaridade através da metodologia project based learning: um estudo de caso no ensino de engenharia. Revista Docência do Ensino Superior, v. 10, p. 1-17, 2020. https://doi.org/10.35699/2237-5864.2020.13597

CROUCH, Catherine Hirshfeld; MAZUR, Eric. Peer Instruction: ten years of experience and results. American Journal of Physics, v. 69, n. 9, p. 970-977, 2001.

https://doi.org/10.1119/1.1374249

ESTEVES, Jéssica Rodrigues; ARAÚJO, Jair Jonko. Aprender e ensinar design digital no contexto da cibercultura: experiência de ensino com metodologias ativas. Revista LatinoAmericana de Estudos em Cultura e Sociedade, v. 6, ed. especial, p. 1-17, 2020. https://doi.org/10.23899/relacult.v6i4.1750

DETERDING, Sebastian; DIXON, Dan; KHALED, Rilla; NACKE, Lennart. From game design elements to gamefulness: defining "gamification". In: INTERNATIONAL

ACADEMIC MINDTREK CONFERENCE: ENVISIONING FUTURE MEDIA ENVIRONMENTS, 15, 2011, New York. Proceedings... New York: ACM, 2011. p. 9-15. https://doi.org/10.1145/2181037.2181040

FARDO, Marcelo Luis. A gamificação como estratégia pedagógica: estudo de elementos dos games aplicados em processos de ensino e aprendizagem. 2013. 160 f. Dissertação (Mestrado em Educação) - Universidade de Caxias do Sul, Caxias do Sul, 2013. Disponível em:

https://repositorio.ucs.br/xmlui/bitstream/handle/11338/457/Dissertacao\%20Marcelo\%20Luis \%20Fardo.pdf? sequence=1\&isAllowed=y. Acesso em: 05 de jul. de 2021.

FALAGAS, Matthew E.; PITSOUNI, Eleni I.; MALIETZIS, George A.; PAPPAS, Georgios. Comparison of PubMed, Scopus, Web of Science, and Google Scholar: strengths and weaknesses. The FASEB Journal, v. 22, n. 2, p. 338-342,

2008. https://doi.org/10.1096/fj.07-9492LSF.

FESTAS, Maria Isabel Ferraz. A aprendizagem contextualizada: análise dos seus fundamentos e práticas pedagógicas. Educação e Pesquisa, São Paulo, v. 41, n. 3, p. 713728, 2015. http://dx.doi.org/10.1590/S1517-9702201507128518

GIORDANO; Cassio Cristiano; SANTOS, Douglas Borreio Maciel dos; SANTOS, Eliana Calixto; GUIMARÃES, Jailma Ferreira. Aprendizagem baseada em projetos e difusão de inovações: um estudo com alunos do ensino médio. Revista de Educação Matemática, v. 3, n. 3, p. 3-24, 2020. https://doi.org/10.30612/tangram.v3i3.7304

GUERRA, João Henrique Lopes. Utilização do computador no processo de ensinoaprendizagem: uma aplicação em planejamento e controle da produção. 2000. $168 \mathrm{f}$. Dissertação (Mestrado em Engenharia de Produção) - Universidade de São Paulo, São Carlos, 
SP, 2000. Disponível em: https://www.teses.usp.br/teses/disponiveis/18/18140/tde-29032001151920/publico/diss_jh.pdf. Acesso em: 05 de jul. de 2021.

HAKE, Richard Robb. Interactive-engagement versus traditional methods: A six-thousandstudent survey of mechanics test data for introductory physics courses. American Journal of Physics, v. 66, n. 1, p. 64-74, 1998. https://doi.org/10.1119/1.18809

HMELO-SILVER, Cindy E.; DUNCAN, Ravit Golan; CHINN, Clark A. Scaffolding and achievement in problem-based and inquiry learning: a Response to Kirschner, Sweller, and Clark (2006). Educational Psychologist, v. 42, n. 2, p. 99-107, 2006.

https://doi.org/10.1080/00461520701263368

KIELT, Everton Donizetti. Utilização integrada do Just-in-time teaching e Peer Instruction como ferramentas de ensino de mecânica no ensino médio mediadas por app. 2017. 111 f. Dissertação (Mestrado em Ensino de Ciência e Tecnologia) - Universidade Tecnológica Federal do Paraná, Ponta Grossa, 2017. Disponível em:

https://repositorio.utfpr.edu.br/jspui/bitstream/1/2470/1/PG PPGECT M Kielt\%2c\%20Evert on\%20Donizetti_2017.pdf. Acesso em: 05 de jul. de 2021.

KNIGHT, Jennifer K.; BRAME, Cynthia J. Peer Instruction. Life Sciences Education, v. 17, n. 2, p. 1-4, 2018. https://doi.org/10.1187/cbe.18-02-0025

LANDERS, Richard N. Developing a theory of gamified learning: linking serious games and gamification of learning. Simulation \& Gaming, v. 45, n. 6, p. 752-768, 2014.

https://doi.org/10.1177/1046878114563660

LARANJEIRA, Jane Maria Gonçalves; BEZERRA, Marayza da Silva; CARVALHO, Lucelma Pereira de; BARBOSA, Joana D'arc dos Santos; SILVA, William Daniel Alves Bezerra da; SILVA, José Renan da. Jornal da química inorgânica: uma estratégia de alfabetização científica. Scientia Naturalis, v. 1, n. 2, p. 235-248, 2019. Disponível em: https://periodicos.ufac.br/index.php/SciNat/issue/view/128. Acesso em: 05 de jul. de 2021.

LENZ, Bob; WELLS, Justin; KINGSTON, Sally. Transforming schools using projectbased learning, performance assessment, and common core standards. 1 ed. San Francisco: Jossey-Bass, 2015.

MACIEL, Mayara Santos. Videoaprendizagem: uma metodologia ativa experimental para o Ensino Superior. 2019. 152 f. Dissertação (Mestrado em Ensino) - Universidade Federal do Pará, Belém, 2019. Disponível em:

http://repositorio.ufpa.br/jspui/bitstream/2011/12162/1/Dissertacao VideoaprendizagemMeto dologiaAtiva.pdf. Acesso em: 05 de jul. de 2021.

MALLMANN, Elena Maria; JORGE, Lóren Kellen Carvalho. Metodologia audiovisual (particip)ativa na formação de professores: produção de videoaulas. Revista de Educação Matemática e Tecnológica Iberoamericana, v. 10, n. 1, p. 1-14, 2019.

https://doi.org/10.36397/emteia.v10i1.240017

MCDONNELL, Lisa; MULLALLY, Martha. Research and teaching: Teaching students how to check their work while solving problems in genetics. Journal of College Science

Teaching, v. 46, n. 1, p. 68-75, 2016. Disponível em: 
https://cwsei.ubc.ca/sites/default/files/cwsei/outcomes/SEIresearch/McDonnellMullally_ProbSolve-Checking JCST2016.pdf. Acesso em: 05 de jul. de 2021.

MILLS, Julie E.; TREAGUST, David F. Engineering education - is problem based or projectbased learning the answer? Australasian Journal of Engineering Education, v. 3, n. 2, p. 216, 2003. Disponível em:

https://www.researchgate.net/publication/246069451_Engineering_Education_Is_ProblemBased_or_Project-Based_Learning the_Answer. Acesso em: 05 de jul. de 2021.

MUNN, Zachary; PETERS, Micah D. J.; STERN, Cindy; TUFANARU, Catalin; MCARTHUR, Alexa; AROMATARIS, Edoardo. Systematic review or scoping review? Guidance for authors when choosing between a systematic or scoping review approach. BMC medical research methodology, v. 18, n. 143, 2018. https://doi.org/10.1186/s12874-0180611-X

NUNES, Marcos Oliveira Sugestão de um processo de avaliação das metodologias ativas de ensino, IPA: índice percentual de aprendizagem. 2019. 87 f. Dissertação (Mestrado em Ciências - Mestrado Profissional em Matemática em Rede Nacional) - Instituto de Ciências Matemáticas e de Computação, Universidade de São Paulo, São Carlos, 2019. Disponível em: https://www.teses.usp.br/teses/disponiveis/55/55136/tde-05022020170848/publico/MarcosOliveiraNunes_revisada.pdf. Acesso em: 05 de jul. de 2021.

OECHSLER, Vanessa; MANERICH, Danielle; SILVA, Felipe Matheus Nogueira da. A relação entre professor e aluno no processo de produção de vídeo em sala de aula. Revista Novas Tecnologias na Educação, v. 17, n. 1, p. 587-596, 2019. https://doi.org/10.22456/1679-1916.95951

OGUZ-UNVER, Ayse; ARABACIOGLU, Sertac. A comparison of inquiry-based learning (IBL), problem-based learning (PBL) and project-based learning (PJBL) in science education. Academia Journal of Educational Research, v. 2, n. 7, p. 120-128, 2014. http://dx.doi.org/10.15413/ajer.2014.0129

OLIVEIRA, Vagner; VEIT, Eliane Angela; ARAÚJO, Ives Solano. Relato de experiência com os métodos Ensino sob Medida (Just-in-Time Teaching) e Instrução pelos Colegas (Peer Instruction) para o Ensino de Tópicos de Eletromagnetismo no nível médio. Caderno Brasileiro de Ensino de Física, v. 32, n. 1, p. 180-206, 2015. https://doi.org/10.5007/21757941.2015v32n1p180

OLIVEIRA, Maria Angélica Figueiredo; LIMA, José Valdeni. Participação ativa em sala de aula por meio de espaços híbridos: um estudo no ensino técnico integrado. Revista

Educacional Interdisciplinar, v. 7, n. 1, p. 1-7, 2018. Disponível em:

https://seer.faccat.br/index.php/redin/article/view/1075/657. Acesso em: 05 de jul. de 2021.

OLIVEIRA, Maria Angélica Figueiredo. Estratégia híbrida para o processo ensinoaprendizagem baseada na participação ativa e avaliações integradas. 2019. $233 \mathrm{f}$. Tese (Doutorado em Informática na Educação) - Universidade Federal do Rio Grande do Sul, Porto Alegre, 2019. Disponível em: https://lume.ufrgs.br/handle/10183/200077. Acesso em: 05 de jul. de 2021. 
PANTOJA, Narjara Vidal; VIEIRA, Iusseny do Nascimento Soares; HANAN, Maria Eduarda Ribeiro. Produção de jornal acadêmico para abordagem dos temas reciclagem e preservação da água no ensino médio técnico. Scientia Naturalis, v. 1, n. 3, p. 183-192, 2019. Disponível em: https://revistas.ufac.br/index.php/SciNat/article/view/2554. Acesso em: 05 de jul. de 2021.

PEREIRA, Zeni Terezinha Gonçalves; SILVA, Denise Quaresma da. Metodologia Ativa: sala de aula invertida e suas práticas na educação básica. Revista Iberoamericana sobre Calidad, Eficacia y Cambio en Educación, v. 16, n. 4, p. 63-78, 2018. https://doi.org/10.15366/reice2018.16.4.004

PIMENTA, Maria Alzira de Almeida. Ética e criatividade: as dimensões do plágio. In: AMARILHA, Marly. (Org.). Educação e leitura: desafios e criatividade. Campinas, SP: Mercado das Letras, 2016.

SACCOL, Amarolinda; SCHLEMMER, Eliane; BARBOSA, Jorge. M-learning e elearning: novas perspectivas da aprendizagem móvel e ubíqua. São Paulo: Pearson, 2011.

SALES, Gilvandenys Leite; CUNHA, Joana Laysa Lima; GONÇALVES, Alexandra Joca; SILVA, João Batista da; SANTOS, Rubens Lopes dos. Gamificação e ensinagem híbrida na sala de aula de física: metodologias ativas aplicadas aos espaços de aprendizagem e na prática docente. Conexões: ciência e tecnologia, v. 11, n. 2, p. 45-52, 2017.

https://doi.org/10.21439/conexoes.v11i2.1181

SAILER, Michael; HOMNER, Lisa. The Gamification of learning: a meta-analysis. Educational Psychology Review, v. 32, p. 77-112, 2020. https://doi.org/10.1007/s10648019-09498-w

SANCHO, Juana Maria; HERNÁNDEZ, Fernando (Orgs.). Tecnologias para transformar a educação. Porto Alegre: Artmed, 2006.

SANTANA, Adriano César. Metodologia para a aplicação da aprendizagem orientada por projetos ( $\mathrm{AOPj}$ ), nos cursos de engenharia, com foco nas competências transversais. 2009. 163 f. Tese (Doutorado em Engenharia Elétrica) - Universidade de Brasília, Brasília, 2009. Disponível em: https://repositorio.unb.br/handle/10482/5234. Acesso em: 05 de jul. de 2021.

SANTOS, Luciana Rocha dos; RIBEIRO, Augusto Gonçalves. Hipermídia no ensino médio técnico como estratégia de aprendizagem. Revista Temática, n. 10, p. 45-58, 2018. https://doi.org/10.22478/ufpb.1807-8931.2018v14n10.42255

SANTOS, Isabela Gomes dos; TEODORO, Renata Cristina Pereira; SADOYAMA, Geraldo; SADOYAMA, Adriana dos Santos Prado. O uso de metodologias ativas no ensino de ciências: um estudo de revisão sistemática. Psicologia, Educação e Cultura, v. 24, n. 3, p. 69-91, 2020. Disponível em: http://hdl.handle.net/10400.26/34676. Acesso em: 05 de jul. de 2021.

SCHMITZ, Elieser Xisto da Silva. Sala de aula invertida: uma abordagem para combinar metodologias ativas e engajar alunos no processo de ensino-aprendizagem. 2016. $185 \mathrm{f}$. Dissertação (Mestrado em Tecnologias Educacionais em Rede) - Universidade Federal de 
Santa Maria, Santa Maria, 2016. Disponível em:

https://repositorio.ufsm.br/bitstream/handle/1/12043/DIS_PPGTER_2016_SCHMITZ_ELIES ER.pdf? sequence=1\&isAllowed=y. Acesso em: 05 de jul. de 2021.

SILVA, João Batista da; SALES, Gilvandenys Leite. Gamificação aplicada no ensino de Física: um estudo de caso no ensino de óptica geométrica. Acta Scientiae, v. 19, n. 5, p.782798, 2017. Disponível em:

http://www.periodicos.ulbra.br/index.php/acta/article/view/3174/2674. Acesso em: 05 de jul. de 2021.

SILVA, João Batista da; ANDRADE, Maria Helena; OLIVEIRA, Rannyelly Rodrigues de; SALES, Gilvandenys Leite; ALVES, Francisco Regis Vieira. Tecnologias digitais e metodologias ativas na escola: o contributo do Kahoot para gamificar a sala de aula. Revista Thema, v. 15, n. 2, p. 780-791, 2018. http://dx.doi.org/10.15536/thema.15.2018.780-791.838

SILVA, João Batista da; SALES, Gilvandenys Leite; CASTRO, Juscileide Braga de. Gamificação como estratégia de aprendizagem ativa no ensino de Física. Revista Brasileira de Ensino de Física, v. 41, n. 4, p. 1-9, 2019. http://dx.doi.org/10.1590/1806-9126-RBEF$\underline{\text { 2018-0309 }}$

SILVA, Leo Victorino da. Tecnologias digitais de informação e comunicação na educação. Revista de Estudos Universitários, Sorocaba, SP, v. 46, n. 1, p. 143-159, 2020. https://doi.org/10.22484/2177-5788.2020v46n1p143-159

SOUSA, Lademe Correia de. Ensino e pesquisa: história local através da produção de jornal. Revista Mosaico, v. 8, n. 2, p. 173-182, 2015. http://dx.doi.org/10.18224/mos.v8i2.4427

SOUZA, Hélio José dos Santos; GARCIA, Flávio Barroca e; SOARES, Gisele Americo; TURRIONI, João Batista; TONIOSSO, José Pedro; COSTA, Luiz Gustavo Galhardo; OLIVEIRA, Rodrigo Coladello de. Aprendizagem ativa baseada em problemas, projetos e times. In: MATTAZOGLIO-NETO, Octavio; SOSTER, Tatiana Sansone. (Orgs.). Inovação acadêmica e aprendizagem ativa. Porto Alegre: Penso, 2017. p. 41-54. Disponível em: https://play.google.com/books/reader?id=tN3XDgAAQBAJ\&pg=GBS.PR2\&hl=ptBR\&lr=\&printsec=frontcover. Acesso em: 06 jul. 2021.

TULLIS, Jonathan. G.; GOLDSTONE, Robert L. Why does peer instruction benefit student learning? Cognitive Research: Principles and Implications, v. 5, p. 1-12, 2020. https://doi.org/10.1186/s41235-020-00218-5

TURPEN, Chandra; FINKELSTEIN, Noah David. The construction of different classroom norms during peer instruction: Students perceive differences. Physical Review Special Topics-Physics Education Research, v. 6, n. 2, p. 1-22, 2010. https://doi.org/10.1103/PhysRevSTPER.6.020123

VALENTE, José Armando. Por que o computador na educação. In: VALENTE, José Armando (Org.). Computadores e conhecimento: repensando a educação. 2 ed. Campinas: Gráfica Unicamp, 1998. p. 29-53.

VALENTE, José Armando. Pesquisa, comunicação e aprendizagem com o computador. O papel do computador no processo ensino-aprendizagem. In: ALMEIDA, Maria Elizabeth 
Bianconcini de; MORAN, José Manuel (Orgs.). Integração das Tecnologias na Educação: salto para o futuro. Brasília: Ministério da Educação - Secretaria de Educação a Distância, 2005. v. 1, p. 22-31.

VIEIRA JUNIOR, Niltom. Planejamento de um ambiente virtual de aprendizagem baseado em interfaces dinâmicas e uma aplicação ao estudo de potência elétrica. 2012. 233 f. Tese (Doutorado em Engenharia Elétrica) - Faculdade de engenharia de Ilha Solteira, Universidade Estadual Paulista, Ilha Solteira, 2012. Disponível em:

https://repositorio.unesp.br/bitstream/handle/11449/100339/vieirajunior n dr ilha.pdf?seque nce $=1 \&$ isAllowed=y. Acesso em: 07 de jul. de 2021 .

XIMENES, Ariel Peixe; SANTANA, Isabel Cristina Higino. Produção de jornal como recurso didático em aulas de ciências na educação de jovens e adultos (EJA). Ensino em Perspectivas, Fortaleza, v. 2, n. 2, p. 1-15, 2021. Disponível em:

https://revistas.uece.br/index.php/ensinoemperspectivas/article/view/4939/4144. Acesso em: 07 de jul. de 2021.

ZINGARO, Daniel; PORTER, Leo. Peer instruction in computing: the value of instructor intervention. Computers \& Education, v. 71, p. 87-96, 2014.

https://doi.org/10.1016/j.compedu.2013.09.015 